\title{
A literatura infantil em sala de aula nos anos iniciais: a importância dos contos
}

\section{RESUMO}

Tiana Andreza Melo Antunes tiandreza2011@gmail.com Universidade Federal do Rio de Janeiro, Rio de Janeiro, Brasil.

Thaís Martins de Oliveira thaismartinsoliv@gmail.com Faculdade CNEC Ilha do Governador, Rio de Janeiro, Brasil.
Este trabalho dedica-se ao estudo da literatura infantil, mais especificamente à importância dos contos dentro de sala de aula nos anos iniciais. Defende-se que é necessário conscientizar os professores de que a literatura não serve apenas como elemento lúdico, mas que, por ser arte, merece um tratamento apropriado e pode ser utilizada como fonte para despertar o gosto pela leitura. Faz-se um pequeno percurso histórico do gênero conto e põe-se em relevo o espaço que deve ocupar dentro da escola. Sobre este último aspecto, expõem-se as opiniões de docentes do ensino fundamental acerca do trabalho com a literatura infantil. Conclui-se que é um gênero que possui diversas contribuições para o ensino, dentre as quais, o desenvolvimento crítico dos discentes.

PALAVRAS-CHAVE: Educação. Literatura infantil. Contos. 


\section{INTRODUÇÃO}

A leitura precisa se tornar prazerosa desde os primeiros momentos na escola, por isso a importância de como deve ser trabalhada e que métodos podem ser utilizados para que se torne atrativa para as crianças, fazendo com que isso se perlongue por sua vida.

Através dos exames feitos nas escolas como a Avaliação Nacional da Alfabetização - ANA, nos anos de 2013 e 2014 ${ }^{1}$, é possível perceber como é pequena a porcentagem de alunos que leem e conseguem interpretar no ensino fundamental. Então, a intenção desse trabalho seria descobrir a contribuição da literatura infantil nos anos iniciais, respondendo a seguinte questão: de que maneira é possível utilizar a literatura infantil como uma ferramenta de incentivo e colaboração no interesse e desenvolvimento dos alunos em sala de aula?

Quando trabalhada de forma lúdica e criativa, a literatura infantil desperta o envolvimento e o encantamento, deixando de ser uma atividade que desagrada aos alunos. Então, o professor que pretende empregar esse recurso precisa estar atento ao modo como vai trabalhar e que métodos pode utilizar para atrair a atenção das crianças. Uma dessas formas é que a história a ser trabalhada precisa estar presente na sala de aula, como se estivesse acontecendo no momento em que é contada (SILVA; ALBUQUERQUE, 2007).

A Literatura, muitas vezes, é dada apenas como mais uma matéria curricular, fazendo com que os alunos vejam as atividades relacionadas a ela como mais uma tarefa a ser realizada. O modo como se trabalha um conteúdo é fundamental para despertar o interesse dos alunos, como afirma Santos: "Ouvir e ler histórias é o caminho para entrar em contato com um mundo encantador, cheio de mistérios e surpresas, na maioria das vezes interessantes e curiosas que cada vez mais, pode nos impulsionar a querer ouvir outra vez". (SANTOS, 2009, p.11-12).

Logo, a leitura deve ser tratada como uma interação entre o texto e o leitor, sendo direcionada para uma participação e interpretação crítica, inserindo o leitor em sua cultura, estimulando sua criatividade, sua independência e seu interesse, fazendo com que a criança possa relacionar as histórias com sua vida e seu cotidiano, ensinando-a a lidar com seus sentimentos e conflitos e estimulando a criação de suas próprias histórias. Assim, "encontra-se reforçado, na atividade de leitura, o papel do leitor enquanto construtor de sentido, utilizando-se, para tanto, de estratégias, tais como seleção, antecipação, inferência e verificação." (KOCH; ELIAS, 2013, p. 13)

O objetivo geral deste estudo é esclarecer como a literatura infantil pode despertar na criança o gosto pela leitura e a vontade de aprender a ler e escrever, tendo a leitura como algo prazeroso, divertido e significativo, já no início de sua vida escolar, contribuindo para o seu aprendizado. Especificamente, também é relevante descrever o papel que a literatura infantil exerce na formação das crianças e estudar o gênero conto em sua forma e função, tendo em vista que é um dos gêneros mais trabalhados no universo infantil.

$\mathrm{Na}$ primeira parte faz-se um breve histórico sobre a literatura infantil brasileira, seu surgimento e desenvolvimento em meio aos marcos de cada época, com os autores que se destacaram e suas primeiras obras. Segue comentando sobre a importância da literatura infantil nas escolas e como ela 
pode contribuir para o desenvolvimento dos alunos em sala de aula. A segunda parte aborda o surgimento dos contos, seu desenvolvimento ao longo dos anos, sua definição e retoma alguns autores que se destacaram em determinadas épocas. A terceira, por sua vez, revela a contribuição da literatura infantil relacionada aos trabalhos feitos em sala de aula e aos objetivos dos Parâmetros Curriculares Nacionais. Por fim, a última seção realiza uma análise sobre entrevistas que foram realizadas com quatro professoras que lecionam no ensino fundamental de uma escola do município do Rio de Janeiro, que teve como enfoque principal saber de que maneira elas utilizam os textos literários e se trabalhar com esse recurso pedagógico influencia no desenvolvimento dos alunos em aula.

\section{HISTÓRICO DA LITERATURA INFANTIL BRASILEIRA}

Para começar a falar sobre a literatura, é importante relembrar sua definição. Neste caso, o ponto de partida é a visão de Coelho, para quem

Literatura é uma linguagem específica que, como toda linguagem, expressa uma determinada experiência humana; e dificilmente poderá ser definida com exatidão. Cada época compreendeu e produziu Literatura a seu modo. Conhecer esse "modo" é, sem dúvida, conhecer a singularidade de cada momento da longa marcha da humanidade, em sua constante evolução. Conhecer a literatura que cada época destinou às suas crianças é conhecer os Ideais e Valores ou Desvalores sobre os quais cada Sociedade se fundamentou (e fundamenta...). (COELHO, 1991, p. 24)

A atividade editorial no Brasil começou oficialmente em 1808, com a implantação da Imprensa Régia, porém, por serem publicações esporádicas, eram insuficientes para caracterizar uma produção literária brasileira regular para a infância. A história da literatura brasileira para a infância só começou com o surgimento da República, que trazia transformações e modernização.

Se a literatura infantil europeia teve seu inicio ás vésperas do século XVIII, quando, em 1967, Charles Perrault publicou os célebres Contos da mamãe Gansa, a literatura infantil brasileira só veio a surgir muito tempo depois, quase no século $X X$, muito embora ao longo do século XIX reponte, registrada aqui e ali, a notícia do aparecimento de uma ou outra obra destinada a crianças. (LAJOLO; ZILBERMAN, 2010, p. 23)

Nesse momento da história nacional, em que há uma urbanização acelerada, surge uma oportunidade para o aparecimento da literatura infantil brasileira, uma vez que diferentes públicos vão se constituindo e para eles diversos tipos de publicações são destinadas.

Com a transformação de uma sociedade rural para a urbana, a escola acaba por exercer um papel fundamental, pois é nela que a sociedade moderna deposita a introdução à infância em seus valores ideológicos, nas habilidades, técnicas e conhecimentos necessários para a produção de bens culturais, abrindo um espaço para a produção didática e literária direcionada ao público infantil. 
A formação da literatura infantil começou a acontecer devido, também, ao modelo econômico daquele Brasil republicano que teoricamente possuía um contingente urbano que consumia bens culturais. Assim como necessitava de instrução e alfabetização que se obtinha pela escola, dava-se prestígio aos esforços pela formação da literatura infantil nacional. Entretanto, em meio à valorização pela instrução e pela escola, há uma preocupação com a carência de material adequado de leitura para crianças brasileiras.

Nas lamentações da ausência de material de leitura e de livros para a infância brasileira, fica patente a concepção, bastante comum na época, da importância do hábito de ler para a formação do cidadão, formação que, a curto, médio e longo prazo, era o papel que se esperava do sistema escolar que então se pretendia implantar e expandir. (LAJOLO; ZILBERMAN, 2010, p. 28).

Diante de muitas reivindicações, a necessidade foi atendida. Intelectuais, jornalistas e professores começaram a produzir livros infantis voltados para os discentes das escolas para que o projeto de um Brasil moderno pudesse ser consolidado. A partir daí, as traduções e adaptações de obras infantis estrangeiras começaram a se multiplicar.

Carlos Jansen e Figueiredo Pimentel são os que se encarregam, respectivamente, da tradução e adaptação de obras estrangeiras para crianças. Graças a eles, circulam, no Brasil, Contos seletos das mil e uma noites (1882), Robinson Crusoé (1885), Viagens de Gulliver (1888), As aventuras do celebérrimo Barão de Münchhausen (1891), Contos para filhos e netos (1894) e D. Quixote de la Mancha (1901), todos vertidos para a língua portuguesa por Jansen. Enquanto isso, os clássicos de Grimm, Perrault e Andersen são divulgados nos Contos da Carochinha (1894), nas Histórias da avozinha (1896) e nas Histórias da baratinha (1896), assinadas por Figueiredo Pimentel e editadas pela livraria Quaresma. (LAJOLO; ZILBERMAN, 2010, p. 29).

Porém essas traduções e adaptações eram editadas em Portugal, portanto fugiam do português brasileiro, fazendo com que o leitor não conseguisse compreender muitas palavras que não condiziam com sua própria língua.

E, mais uma vez, a criação de uma literatura infantil brasileira se faz necessária. Desse modo, surgem vários programas de nacionalização do acervo literário europeu para a criança. Em 1915 foi inaugurada a Biblioteca Infantil pela editora Melhoramentos, sob a direção do educador Arnaldo de Oliveira Barreto, que publicou como primeiro volume de sua coleção $O$ patinho feio, de Hans Christian Andersen.

O projeto pedagógico criado para ser trabalhado aliado à literatura infantil tinha o objetivo de que os leitores reproduzissem passivamente o comportamento, atitudes e valores que os textos manifestavam. Dá-se destaque ao livro Através do Brasil, em 1910, de Olavo Bilac e Manuel Bonfim, que contava a história de dois irmãos em busca de parentes distantes após a morte do pai e cuja narrativa, de acordo com Bilac, serviria para se dar aula sobre diversas disciplinas, como geografia ou higiene, por exemplo.

A representação da literatura infantil não condizia com as representações não infantis da época, pois omitia as variações econômicas e culturais do Brasil. 
Porém a recuperação dessas representações foi realizada por uma literatura infantil anterior a 1920, pelo trabalho de Alexina de Magalhães Pinto, com um projeto de leitura que permitia às crianças acesso a um material folclórico representado por cantigas, histórias, provérbios e brinquedos recolhidos pela autora e publicados na coleção Icks de Biblioteca Escolar. Por esse material era possível notar a dificuldade com que os educadores da época lidavam com as diversidades culturais do Brasil.

No fim do século XIX - também é relevante afirmar - houve uma preocupação com a correção da linguagem presente nas obras literárias, abandonando os modelos clássicos portugueses. Nesse momento, a literatura destinada a crianças, além de transmitir exemplos de valores e atitudes, transmitiria a correção da linguagem, pois falar bem a própria língua era considerado um dever. Essa exigência impedia a manifestação linguística de determinados personagens infantis que eram humildes ou não escolarizados por se distanciarem do padrão culto utilizado pela classe dominante.

A literatura infantil estava restrita às imposições que a escola e a sociedade esperavam dela, não se aliando às conquistas da literatura não infantil que representavam os exemplos da época, que nem sempre eram apresentados nos livros infantis.

\subsection{A IMPORTÂNCIA DA LITERATURA INFANTIL NAS ESCOLAS}

Pelo ponto de vista de Coelho (1991, p. 24), "Literatura Infantil é, antes de tudo, literatura; ou melhor, é arte: fenômeno de criatividade que representa o Mundo, o Homem, a Vida, através da palavra. Funde os sonhos e a vida prática; o imaginário e o real; os ideais e sua possível/impossível realização...".

Essa literatura desperta, portanto, o imaginário da criança, sendo assim um recurso atraente e criativo para ser utilizado em sala de aula. Por isso, é importante que essa prática de ouvir, ler e contar histórias não deixe de existir.

[...] acreditamos que toda criança precisa ter a oportunidade de ouvir alguém contando histórias, ter livrinhos e ser estimulada a criar suas próprias histórias. Sabemos que a prática desse hábito, tão comum às gerações anteriores, hoje, não só devido aos meios de comunicação de massa, mas também às próprias mudanças do diaa-dia familiar que conhecemos, não é frequente, sendo por vezes, inexistente na maioria dos lares. (SILVA; ALBUQUERQUE 2007, p. 55 e 56).

Essa motivação pela leitura pode começar por atividades que apresentem os personagens, sendo associados à vida dos alunos, com a apresentação dos títulos das histórias, provocando a curiosidade e a criatividade ao imaginar a continuidade e os finais possíveis para a obra apresentada.

Os projetos que envolvem a Literatura, como contação de histórias, teatro e música são capazes de estimular os alunos a aprender determinados conteúdos de maneira agradável, dando a eles independência e propiciando o desenvolvimento de seus desejos e pensamentos.

Muitas vezes, as obras literárias não são trabalhadas em sala de aula como uma leitura lúdica e criativa e, sim, como uma leitura tediosa que não instiga o 
lado crítico do aluno, não despertando nele a emoção da história lida. O que interfere na maneira como o aluno vai encarar a atividade é o modo como o professor ministra o conteúdo proposto. Se ele for trabalhado só como algo que é obrigatório, que faz parte da disciplina e não for levado como algo diferente, atrativo, que desperte a vontade de fazer e aprender, não trará bons resultados. Já se for transmitido como algo que prenda sua atenção, de forma divertida, que os motive a praticar, aí sim atingirá bons resultados.

Mesmo quando é escolhida uma obra de qualidade literária e que interesse aos alunos, se o professor se restringe a fichas e provas, acaba por perder a oportunidade de motivar a leitura e mostrar como se constrói o texto.[...] Assim, o texto literário, que poderia ajudar o trabalho dos professores, acaba sendo considerado por eles e seus alunos como apenas uma atividade a mais, e perde-se, dessa forma, a oportunidade de incentivar a leitura. Em vez disso, para formar leitores, poderíamos proporcionar ao aluno uma variedade de leituras e a possibilidade de se sentir o agente do ato de ler, para que essa não seja apenas uma atividade a mais no currículo escolar. (SANTOS, 2010, p. 41- 42).

A leitura deve ser trabalhada desde cedo com a criança, começando em casa, com a família, para que na escola seja dada continuidade a esse trabalho, mostrando tudo o que pode ser desenvolvido na criança através da leitura e como ela pode contribuir para o seu aprendizado.

A dificuldade enfrentada pelos professores mostra um problema que, na verdade, começa muito cedo, pois considera-se que a criança entra em contato com a leitura apenas quando chega à escola: a família não tem o hábito de ler, livros não são considerados presente e ensinar a ler é tarefa do professor.[...] (SANTOS 2010, p. 43).

O momento da contação de histórias precisa ser um momento único, agradável, para que possa ficar guardado na memória dos alunos, assim como o ambiente onde a história é contada. Assim, em um momento alunos e professores podem ser ouvintes e em outro momento contadores de histórias, podendo repassar toda a magia e emoção que lhes foram transmitidas assim como o aprendizado adquirido, construindo uma relação prazerosa e divertida entre a leitura e a literatura, formando crianças que gostam de ler.

\section{O CONTO: BREVE HISTÓRICO E DEFINIÇÃO}

A respeito da necessidade de contar, Charaudeau (2012) nos afirma que as narrativas estão imbuídas de uma intencionalidade e podem ser agrupadas em dois tipos: (i) as narrativas de unidade do ser, que assentam numa verdade única, representadas, por exemplo, nas fábulas, contos de fada e textos sagrados, em que há "uma idealização que deve provocar fascinação e desejo de identificação com um outro si-mesmo" (CHARAUDEAU, 2012, p. 155); (ii) as narrativas de pluralidade do ser, que se constituem na concepção da impossibilidade de recuperação do todo, da unidade do ser e que, portanto, se baseiam em fragmentos de verdade, como por exemplo, as novelas. 
O conto, que se insere no primeiro grupo, é uma narrativa de pequena extensão, que possui como características tratar de uma determinada situação e acompanhá-la com o objetivo de chegar ao seu desfecho, organizando os detalhes do texto de forma que prenda a atenção do leitor. Trata-se de um gênero com tempo e espaço limitados, com poucos personagens.

Esse gênero surgiu a partir de narrativas religiosas, que contavam histórias sobre santos e personagens míticas e com o tempo foram sendo enriquecidas, como afirma SOARES (2003, p. 85): “[...] Mais tarde estas pequenas narrativas foram sendo enriquecidas com elementos oriundos do folclore, surgindo então, seres fantásticos, tão ao gosto popular, como os dragões, os duendes e as fadas $[\ldots]^{\prime \prime}$.

Após a criação e expansão do gênero, suas próprias leis foram criadas e qualquer assunto poderia ser transformado em conto, desde que obedecesse às regras de economia e de objetividade. O conto pode designar duas formas de narrativa: a forma popular, folclórica, que não é atributo de um único autor, mas de uma criação coletiva; e a forma artística, que pertence a um estilo individual.

\footnotetext{
O mesmo não ocorre em outras línguas. O inglês utiliza a denominação "tale" para o conto folclórico, popular e "short-story" para narrativas com características eminentemente literárias. Em alemão emprega-se "novelle" e "erzahlung" para as mesmas narrativas a que o inglês chama "short-story" e "marchen" para os contos populares. Assim, em italiano encontramos também duas formas: "novelle" e "racconto". (REIS, 1984, p. 11)
}

Segundo Reis (1984), no mundo atual, onde há tecnologia e outros meios pelos quais a sociedade pode se distrair em meio ao cansaço do dia a dia, o conto popular acaba perdendo espaço para a comunicação auditiva e visual, que acaba se tornando mais cômoda. Então, os contos acabam ficando restritos aos ambientes rurais, nos quais o encanto e o comodismo da comunicação ainda não chegaram e a imaginação ainda é despertada por uma roda de conversa em volta de uma fogueira. No entanto, o conto ainda está presente no ambiente urbano, seja nas escolas, nas rodas de contação de histórias ou em determinada atividade proposta em sala de aula, seja pelos leitores que apreciam o gênero ou até mesmo em casa quando a família narra os contos para as crianças antes de dormir.

No final do século XVIII, o conto popular tornou-se objeto de estudo daqueles que estudavam as manifestações folclóricas, espontâneas do povo. E o estudo que ganhou maior atenção nas universidades foi o do russo Wladimir Propp, que constatou que diferentes personagens, com diferentes características, possuíam as mesmas ou equivalentes ações. $O$ fato de haver sempre um herói e uma proibição que ele não poderia infringir, além de outros elementos que permaneciam iguais, sem nenhuma variação, comprovou uma estrutura comum a todos os contos folclóricos.

Entretanto, esse gênero como experiência literária é controverso. A partir do Romantismo, o gênero começa a ganhar autonomia, adquirindo uma forma aberta, experiências e inovações, esquivando-se de concepções fechadas e inscrevendo-se em realizações artísticas como o romance e a poesia modernos. 
No Brasil, por exemplo, com a abertura representada pela proposta literária do Modernismo, tantas são as discussões acerca do que é ou não é conto, que o escritor paulista Mário de Andrade (18931945) - que tanto bebeu no universo mitológico popular para a criação do seu Macunaíma começa o primeiro conto do livro Contos Novos 'lavando as mãos', como se poderia dizer: 'Tanto andam agora preocupados em definir o conto não sei bem si o que vou contar é conto ou não, sei que é verdade'. (REIS, 1984, p. 17).

O movimento modernista caracterizava-se por valorizar nos códigos artísticos e literários inovações que atingissem as várias categorias da linguagem, estando acessível às aventuras experimentais das vanguardas. Mário de Andrade unia à prática de contos uma formação cultural rica e admirável que permitia discutir teoricamente a questão do conto como uma forma narrativa. Indo contra posturas normativas predeterminadas que impediam qualquer atitude inovadora.

Pode-se, então, afirmar que o conto, tanto como manifestação artística ou como gênero literário, passou por um processo de transformação, foi atualizado e reformulado ao longo do tempo, tendo suas produções valorizadas e entendidas de acordo com a época.

Em princípio, o conto se caracteriza por ser uma narrativa curta, um texto em prosa que dá o seu recado em reduzido número de páginas ou linhas. Mas não seria um simplicionismo defini-lo apenas pelo tamanho? Não é bem isto. Ocorre, porém, que a forma conto apresenta como sua maior qualidade o fator concisão. Concisão e brevidade. Assim o dado quantitativo é mera decorrência do aspecto qualitativo do texto. Curto porque denso. (REIS,1984, p. 23).

\subsection{OS CONTOS DE FADAS}

Os contos de fadas foram compostos para a literatura infantil europeia durante a Idade Média e Moderna. E, a partir do século XVII, esse gênero foi recontado por escritores como Perrault, La Fontaine, e os Irmãos Grimm, que traduziram os contos para os dias atuais. Vale destacar a importância de Charles Perrault ${ }^{2}$ justamente para gerar a preferência pelos contos de fada e por ser responsável por difundir a literatura infantil em seu tempo.

A literatura infantil passou a ser dedicada a crianças quando surgiu a Modernidade, no Ocidente. Estava relacionada à mudança de como a sociedade observaria as crianças. Embora algumas criações fossem surgindo ao longo da história, os contos produziram uma marca decisiva na literatura infantil. Desse modo, essas histórias foram moldadas e remodeladas para as crianças e adultos.

Ao escutar expressões como "era uma vez...", "há muito tempo atrás", é comum que já surja uma expectativa de uma história bonita, fantasiosa e mágica. As fadas são consideradas seres de inspiração mitológica, com poderes especiais. Tudo que é humanamente impossível torna-se permitido e realizável com uma varinha de condão, objetos encantados e talismãs.A construção dos contos de fadas ainda tem seu espaço na sociedade atual, apesar de ter sofrido várias mudanças para atender às exigências da linguagem moderna. O modo como foram escritos permite que possamos observar como a realidade foi transmitida para os livros infantis, possibilitando ao leitor a atualização constante, trazendo a 
obra para seu presente, sem perder de vista sua época de construção. Portanto, é possível asseverar que, a partir da década de setenta, a literatura destinada a crianças também tem se voltado para textos pautados no "verismo [que] evidencia a preocupação de reproduzir, o mais fielmente possível, a realidade, retratando - e denunciando - os problemas da sociedade brasileira" (MICHELLI, 2012, p. 33-34). Entretanto, o movimento mais relevante se encontra na interseção entre o que é fantasioso e o que se baseia na realidade nacional, desse modo, "a contemporaneidade geralmente abole visões polares e maniqueístas" (MICHELLI, 2012, p. 36) Sendo assim, a literatura ao longo desse tempo vem tomando outras direções, visando uma nova consciência de mundo, assim, perdendo a pura exemplaridade ou a transmissão de valores já definidos ou sistematizados.

\section{A CONTRIBUIÇÃO DOS TEXTOS LITERÁRIOS EM SALA DE AULA}

\subsection{PERCEPÇÃO SOBRE LITERATURA RELACIONADA AOS OBJETIVOS DOS PCN}

De acordo com os Parâmetros Curriculares Nacionais (1997), destinados ao primeiro segmento do ensino fundamental, os textos ensinados nas escolas estão descontextualizados com a realidade dos alunos. São vistos como um agregado de frases, cujo objetivo em aula é que o aluno aprenda a ler, com uma sequenciação de conteúdos que é denominada por aditiva, na qual se ensina a juntar letras ou sílabas para formar palavras, palavras para formar frases e frases para formar textos. Desse modo, não é possível que o aluno aprenda a interpretar e construir textos porque esse método de ensino não está relacionado com a competência discursiva. Frases e palavras podem ser enfatizadas em determinadas situações, mas não podem ser somente apresentadas isoladas de seu contexto.

Houve uma visão de que o texto indicado para os iniciantes na leitura seriam os textos curtos, com poucas frases, entretanto esses pequenos textos não permitem que o leitor possa se divertir, se comover, deixar sua imaginação fluir. Logo, entende-se que o gosto pela leitura não é despertado por textos pequenos, mas sim, por textos que interfiram em suas vidas.

O texto literário é considerado uma forma específica de conhecimento, pois possui propriedades compositivas que constituem a experiência humana e devem ser ensinadas, mostradas e discutidas, uma vez que possuem diversas manifestações. Ele é capaz de expressar a realidade e transgredi-la para o imaginário, há uma relação de aproximação e afastamento da realidade, na qual as invenções de linguagem, a expressão das subjetividades, o trânsito das sensações, os mecanismos ficcionais podem estar misturados a procedimentos racionais, referências indiciais e citações do cotidiano do mundo humano. Sendo assim, o ensino do texto literário deve ser repensado como nos PCN:

A questão do ensino da literatura ou da leitura literária envolve, portanto, esse exercício de reconhecimento das singularidades e das propriedades compositivas que matizam um tipo particular de escrita. Com isso, é possível afastar uma série de equívocos que costumam estar presentes na escola em relação aos textos literários, ou seja, tratá-los como expedientes para servir ao ensino das boas 
maneiras, dos hábitos de higiene, dos deveres do cidadão, dos tópicos gramaticais, das receitas desgastadas do "prazer do texto", etc. Postos de forma descontextualizada, tais procedimentos pouco ou nada contribuem para a formação de leitores capazes de reconhecer as sutilezas, as particularidades, os sentidos, a extensão e a profundidade das construções literárias. (BRASIL, 1997, p. 30).

Durante os oito anos do ensino fundamental, de acordo com os PCN (1997), espera-se que os alunos adquiram progressivamente uma competência em relação à linguagem que Ihes possibilite resolver problemas da vida cotidiana, ter acesso aos bens culturais e alcançar a participação plena no mundo letrado. Para que essa expectativa se concretize, o ensino de Língua Portuguesa deverá organizar-se de modo que os alunos atinjam determinados objetivos, que também podem ser alcançados através do trabalho com os textos literários.

O contato com as histórias permite que a criança ganhe mais experiência, tenha seus instintos despertados, reconheça esses sentimentos que são causados por acontecimentos da vida. Esse contato permite que aspectos como caráter, raciocínio, imaginação, criatividade, senso crítico e disciplina sejam trabalhados e desenvolvidos no aluno. Busca-se despertar o interesse por ler ou ouvir especialmente de textos literários e informativos e por compartilhar opiniões, ideias e preferências mesmo que seja com a ajuda do professor; fazer empréstimos de livros do acervo da classe e da biblioteca escolar; trabalhar com o cuidado com os livros e outros materiais; e ensinar a se preocuparem com a qualidade de suas próprias produções escritas, tanto no que se refere aos aspectos textuais como à apresentação gráfica. Contribui-se para o seu desenvolvimento em sala, seu relacionamento com o professor e seus colegas de uma forma didática e descontraída, já que as crianças costumam apreciar as histórias. Esse contato com a leitura pode ser trabalho por meio dos contos, que é um dos gêneros que mais atrai as crianças, como pontua Oliveira:

[...] ao trabalhar com a leitura é possível utilizar-se do recurso dos contos de fada, uma vez que só estas histórias que permeiam a vida de muitas crianças. Através dos desenhos animados, do relato verbal, dos contos lidos em sala de aula, a criança estará sendo estimulada a compreender por si só e a ler as histórias que tanto a encantam. Ao pensar este recurso na escrita como modelo, vê-se a possibilidade de a criança escrever a sua própria história. Em absoluto, são recursos que podem ser explorados pelo professor no ensino, incentivando a participação ativa. (OLIVEIRA, 2008, p. 43-44).

Sendo assim, a criança é capaz de compreender que existe momento para tudo: seja para brincar, para estudar, conversar e prestar atenção, tendo compreensão de que estudar é importante e que vale a pena. Ainda de acordo com os PCN (1997), o trabalho com os contos permite que todos esses aspectos possam ser desenvolvidos em sala de aula, pois ele é adequado tanto para o trabalho com a linguagem oral, tanto para com a linguagem escrita.

O aluno interpreta o que compreende, e não a explicação. Esta compreensão é o que permite a análise do texto, sendo esta o instrumento de aprendizagem (Bruner, 2001). É possível pensar isto à luz dos contos de fada, já que neste processo a análise é fundamental para o trabalho com os contos. Interpretações 
alternativas podem ser aplicadas aos contos, o que promove diversidade, proporcionando ao aluno interpretar e dialogar a partir de diferentes pontos de vista. (OLIVEIRA, 2008, p. 40).

\subsection{A LITERATURA INFANTIL COMO UM RECURSO PARA A PRÁTICA DOCENTE}

Como já foi mencionado no decorrer desse trabalho, o modo como o professor trabalha as histórias em sala de aula tem muita influência no interesse dos alunos. Baseada na obra Literatura infantil e juvenil na prática docente, de Martins, Santos e Gens (2010), é possível destacar possíveis sugestões que despertam a curiosidade e o interesse dos alunos pela leitura e pela escrita quando relacionadas ao uso das narrativas.

Primeiramente, a apresentação do título, da capa e dos personagens é fundamental para aguçar a curiosidade dos leitores, assim como a apresentação dos personagens e a leitura de um pequeno trecho do texto.

Ao começar a leitura da história, é importante que o professor faça com que os alunos tentem desvendar as relações existentes entre os personagens, assim como suas características, trabalhando com a argumentação dos discentes, fazendo com que justifiquem suas opiniões. Também é interessante que os alunos possam ler e não apenas ouvir, assim é possível perceber a interpretação de cada um. No decorrer da história, também é interessante verificar o enredo, as incoerências (caso existam), as estratégias de construção do texto, a pontuação, a organização dos parágrafos. E esse trabalho de análise deve ser feito em conjunto entre professor e alunos.

As manifestações de sentimentos e consequências desses sentimentos e atos presentes na história também podem ser trabalhados e o que pode interferir no comportamento das pessoas e o que pode influenciar em suas características. A percepção da divisão de cada momento no texto também permite identificar as características do gênero, no caso proposto, o conto, sua organização, sua estrutura e suas principais características.

Em momentos de suspense da história, é interessante que haja pausas e propostas de possíveis situações descritivas que possam acontecer após determinado acontecimento. É possível retomar as perguntas já feitas anteriormente, antes da história ser contada e ver a diferença entre as respostas, fazendo com que os alunos listem as atividades dos personagens e descrevam suas opiniões sobre cada uma.

Pode ser discutida na turma qual a diferença que conseguem perceber quando o texto é narrado por diferentes personagens, o que pode ser considerado verdade, qual narração transmite maior confiança, é mais divertida, mais formal, mais tenebrosa, qual se assemelha a uma narração de uma criança ou de um adulto.

E, para finalizar, é interessante pedir que os alunos possam reescrever a história em forma de peças teatrais ou de quadrinhos, ilustrando o conto, elogiando ou criticando o comportamento dos personagens, atribuindo diferentes desfechos, dando continuidade a história e apresentando suas criações para as outras turmas ou em determinadas atividades da escola. Deve-se tornar o ato de ler e escrever algo interessante para todos, fazendo com que os 
alunos possam utilizar sua criatividade, atribuir sentido aos textos e não apenas decodificá-los, utilizando seus conhecimentos, textuais, intertextuais e de vivência pessoal.

\section{A CONCEPÇÃO DOCENTE SOBRE OS TEXTOS LITERÁRIOS: ANÁLISE DE ENTREVISTAS}

Duas questões trazidas por Regina Micheli continuam, a nosso ver, no âmago das inquietações sobre o espaço da literatura infantil (e dos contos, especificamente), que indagam, em primeiro lugar, o porquê de trabalhar com as histórias maravilhosas ou fantásticas e, em segundo lugar, o que explicaria a perenidade desse gênero. Sobre a primeira, afirma-nos a autora que "o texto literário, por sua literariedade e sua plurissignificação, instiga descobertas, permite viagens insuspeitadas" (MICHELLI, 2012, p. 51) e a respeito da segunda indagação, retorna - poderíamos afirmar - ao pensamento de Charaudeau, para quem o ser humano tem necessidade de contar para se entender no mundo, para procurar respostas sobre si mesmo e sobre suas origens. E, desse modo, a partir do universo infantil, os contos fomentam a realidade vinda de um universo artístico e prazeroso.

Para saber a percepção dos professores com relação ao trabalho realizado nas escolas com os textos literários - e, de algum modo, como esse espaço de "descobertas" dos contos se dá -, foram realizadas, em uma escola municipal na Ilha do Governador (zona norte do Rio de Janeiro), entrevistas com quatro professoras do ensino fundamental: três delas são responsáveis cada uma por duas turmas do primeiro, segundo e terceiro ano do ensino fundamental; a quarta trabalha na sala de leitura da escola (primeiro ao quinto ano).

De acordo com as entrevistas, percebeu-se que é possível trabalhar com a literatura infantil em sala de aula de forma lúdica, prazerosa, envolvente, acrescentando e contribuindo significativamente em todos os aspectos, tanto para o professor quanto para o aluno. Mais ainda, ver que essa possibilidade não existe só na teoria, nos livros, não é apenas uma hipótese, mas acontece na realidade, no dia a dia das escolas e funciona. O uso da literatura torna o ambiente escolar mais agradável para os alunos não só na hora da recreação, mas na hora de aprender novos conteúdos também, formando e ensinando-os a serem pessoas conscientes, críticas que buscam conhecimento, que têm prazer em ler, em aprender, melhorando o desempenho das crianças e auxiliando no seu desenvolvimento. É possível trabalhar e desenvolver os objetivos propostos nos PCN assim como as propostas de trabalho já descritas no desenvolvimento dessa pesquisa, atingindo aos objetivos propostos. E tudo isso tendo a literatura como ferramenta e como um instrumento facilitador no processo de ensinoaprendizagem.

Todas as respostas foram semelhantes e as entrevistadas concordaram que, quando a literatura infantil é trabalhada em conjunto com as atividades propostas em sala de aula, o desempenho dos alunos melhora significativamente, melhorando a atenção, a concentração, interação com o professor e com a turma e apreensão dos conteúdos. Além disso, permite que vários aspectos do processo de ensino-aprendizagem sejam trabalhados, como: leitura, escrita, interpretação, oralidade, entre outros. Como na resposta da professora M.V: 
Os alunos são capazes de melhorar seu desempenho quando a literatura infantil é trabalhada em conjunto com as atividades propostas em sala de aula, pois a atenção, o foco, a concentração, são trabalhadas, levando a uma melhor concentração e apreensão dos conteúdos.

Com a relação à prática de utilizar histórias que estejam relacionadas ao cotidiano e à vida dos estudantes, todas as professoras concordam que isso é capaz de melhorar o estímulo dos alunos em sala, pois, assim, eles podem demonstrar sua opinião sobre o tema abordado, se interessando cada vez mais. É possível levá-los à reflexão e autoanálise, uma vez que a estimulação é desenvolvida por meio da curiosidade e entusiasmo por temas relacionados com sua vida. Como na resposta da professora M.H.

A estimulação é desenvolvida através do interesse a temas relacionados coma sua vida e cotidiano.

Todas as entrevistadas consideraram que o modo de se contar uma história é bastante importante e interfere no encanto e entusiasmo da criança. Ler a história com a entonação adequada torna o interesse do aluno maior; quanto mais teatral e lúdica for a performance e interpretação do narrador, melhor será o rendimento e a conexão com o ouvinte, quanto maior a ênfase na fala dos personagens, mais interessados e estimulados irão ouvir a história.

Ainda sobre o aspecto no qual o gênero conto pode ser utilizado para contribuir na aprendizagem e na transmissão de valores para os alunos, todas as professoras afirmaram que utilizam o gênero em sua prática docente e que ele influencia na formação moral, na criatividade e na imaginação, levando o aluno à reflexão e ao entendimento de suas ações e dos outros colegas, levando-os, também, ao autoconhecimento. Então, pela admiração deles pelos personagens fica mais fácil utilizá-los como exemplos positivos. Como na resposta da professora A.W.

De uma forma subjetiva, não tão direta, os contos, que, na maioria das vezes, são imaginários auxiliam aos professores na intervenção e inclusão de valores que para alguns alunos nem são vivenciados por eles. Pela admiração das crianças aos personagens, fica mais fácil de utilizá-los como exemplos positivos.

Também é importante destacar que todas as docentes trabalham com todos os tipos de histórias, tanto os clássicos como as histórias atuais, pois todas são capazes de transmitir valores morais, despertando o senso crítico dos alunos, dando suporte a todas as disciplinas que são ministradas em aula e enriquecendo o trabalho realizado entre alunos e professores. Como registra a professora M.V dando ênfase a sua admiração pelo trabalho com a literatura:

Utilizo todos os tipos de histórias, principalmente as que enfocam moral e valores, como as fábulas. O universo da literatura é apaixonante, prazeroso e lúdico e, obrigatoriamente, tem que fazer parte do cotidiano escolar. Ele dá suporte ao conteúdo que entremeiam com todas as matérias, enriquecendo o dia a dia escolar. 
Desse modo, foi possível concluir que trabalhar com a literatura infantil aliada aos outros conteúdos em sala só traz benefícios. Essa prática enriquece o trabalho do professor, favorece a aprendizagem dos alunos, torna as disciplinas mais atraentes, transforma as aulas em momentos produtivos, prazerosos, possibilitando o ensinamento de novos conteúdos de forma interessante e facilitando a aprendizagem. Por isso, corroboramos com a função designada ao educador, segundo Francia (2009)

O educador é o homem que deve perceber a realidade com suas tendências e possibilidades, nem tanto para defender as novas gerações, mas sim para prepará-las, para fazer despertar o seu potencial. $O$ educador é o mais indicado e quem mais se vê obrigado a saber que a imaginação, o símbolo e a arte não são apenas realidade, mas também fontes de realidade, às vezes mais humanas e humanizadoras. (FRANCIA, 2009, p. 7)

\section{CONCLUSÃO}

Esse trabalho procurou destacar as principais fontes sobre a origem, o desenvolvimento e a contribuição da literatura infantil brasileira e dos contos para a formação e desenvolvimento da criança na escola ao longo dos últimos séculos. Buscou-se explicar, de maneira breve, a contextualização histórica da literatura infantil brasileira e dos contos, onde, em que momento e como surgiram, suas principais influências e mudanças.

Foi possível compreender que a literatura infantil brasileira passou por diversas alterações em cada época da história, foi bastante influenciada pelos acontecimentos político-sociais e, na maior parte do tempo, o que ela continha e para quem deveria transmitir era determinado pela classe dominante e por seus interesses, muita vezes excluindo as classes mais pobres, possuindo uma linguagem que não as atingia e nem as representava. Mas ao longo do tempo, isso foi sendo mudado a ponto de alcançar todos os públicos, uma vez que era necessário que a população obtivesse instrução e alfabetização. Entretanto, seus objetivos ficavam limitados aos interesses da escola.

O estudo também permitiu compreender que contar histórias não é apenas abrir um livro e ler várias palavras ou mostrar diversas figuras às crianças e sim saber despertar sua curiosidade, instigar sua imaginação, desenvolver seu intelecto, sua criatividade e suas habilidades, porque enquanto diverte a criança, o texto literário favorece o seu desenvolvimento e melhora o seu desempenho.

Outro aspecto bastante relevante identificado no decorrer da pesquisa é que as crianças se encantam pelas histórias porque elas lhes direcionam para a descoberta de sua identidade e comunicação e também sugerem as experiências que são necessárias para desenvolver ainda mais a formação do seu caráter. E os professores podem utilizar as histórias como instrumento para que esses aspectos possam ser desenvolvidos.

Sendo assim, é possível retornar ao questionamento que guiou esta pesquisa: de que maneira é possível utilizar a literatura infantil como uma ferramenta de incentivo e colaboração no interesse e desenvolvimento dos alunos em sala de aula? É possível quando o professor utiliza essa ferramenta de forma didática - assumindo o papel de educador, consoante apontamos em 
Francia (2009) -de forma que o aluno se interesse pelo o que está aprendendo, permitindo que ele participe, interfira, opine de forma crítica, recrie histórias, crie suas próprias histórias, sem se sentir obrigado a realizar uma tarefa apenas porque o professor o impôs ou porque tem um determinado valor em sua nota.

A entrevista realizada com as professoras contribuiu para comprovar que o objetivo geral dessa pesquisa pode ser atingindo, já que é possível despertar na criança o gosto pela leitura e a vontade de aprender a ler e escrever. Todas afirmaram que a literatura é um recurso valioso que contribui significativamente para o seu trabalho e que as crianças se envolvem e adoram.

Por fim, advoga-se que a literatura infantil pode ser utilizada como um desses recursos quando trabalhada de modo que os alunos se interessem e não apenas como mais uma obrigação curricular da escola. Em outras palavras, quando é tratada como arte e seu consequente papel estético. 


\title{
The children's literature in a classroom in initial years: the importance of the tales
}

\begin{abstract}
This work is dedicated to the study of children's literature, more specifically to the importance of stories within the classroom in the early years. It is argued that it is necessary to make teachers aware that literature is not only a playful element, but that, because it is art, it deserves an appropriate treatment and can be used as a source to awaken a taste for reading. A short history of the history genre is made and the space it occupies within the school is emphasized. On the latter aspect, the opinions of primary school teachers about working with children's literature are exposed. It is concluded that it is a genre that has several contributions to teaching, among them, the critical development of the students.
\end{abstract}

KEYWORDS: Education. Children's literature. Tales. 


\section{NOTAS}

${ }^{1}$ PAINEL EDUCACIONAL MUNICIPAL/ ENSINO FUNDAMENTAL- ANOS INICIAIS. Rio de Janeiro, 2014. Disponível em: <http://ana.inep.gov.br/ANA/>. Acesso em: 30 nov. 2016.

2 É interessante a obra Contos de mamãe gansa (PERRAULT, 2012), que permite conhecer versões menos difundidas de contos como "Chapeuzinho Vermelho", bem como compreender o contexto social dos camponeses e da burguesia no século XVII.

${ }^{3}$ Indicamos esta obra para professores que queiram exemplos de como trabalhar o gênero fábula, uma vez que o autor separa sessenta fábulas, com temas variados e indica questões que podem ser inseridas em sala de aula.

\section{REFERÊNCIAS}

BRASIL. Parâmetros Curriculares Nacionais: Língua Portuguesa. Ensino Fundamental. 1a a 4a SÉRIES. Brasília: MEC/SEF, 1997.

CHARAUDEAU, Patrick. Linguagem e discurso: modos de organização. Tradução de Angela M. S. Corrêa; Ida Lúcia Machado. 2 ed. São Paulo: Contexto, 2012.

COELHO, Nelly Novaes. Literatura infantil: teoria, análise, didática. São Paulo: Editora Ática, 1991.

FRANCIA, Alfonso. Educar com fábulas. São Paulo: Editora Mundo Mirim, 2009.

$\mathrm{KOCH}$, Ingedore V.; ELIAS, Vanda M. Ler e compreender: os sentidos do texto. 3 ed. São Paulo: Contexto, 2013.

LAJOLO, Marisa; ZILBERMAN, Regina. Literatura Infantil Brasileira Histórias e Histórias. São Paulo: Ática, 2010.

MICHELLI, Regina. Contos fantásticos e maravilhosos. In: GREGORIN FILHO, José N. (Org.) Literatura infantil em gêneros. São Paulo: Editora Mundo Mirim, 2012.

OLIVEIRA, Tatiana Lopes. A importância dos contos de fada no processo de ensino-aprendizagem. Brasília, 2008. Disponível em: < http://repositorio.uniceub.br/bitstream/123456789/2690/2/20460180.pdf> Acesso em: 18 mai. 2017. 
REIS, Luzia Maria. O que é conto. São Paulo: Brasiliense, 1984.

SANTOS, Célia de Jesus. A contribuição da literatura infantil na formação do préleitor no centro municipal de educação infantil Dr. Álvaro da Franca Rocha.

Salvador, 2009. Disponível em:

<http://www.uneb.br/salvador/dedc/files/2011/05/Monografia-CELIA-DE-JESUSSANTOS.pdf>. Acesso em: 24 nov. 2016.

SANTOS, Leonor Werneck. Leitura na escola: textos literários e formação do leitor. In: MARTINS, Georgina; SANTOS, Leonor Werneck; GENS, Rosa. Literatura infantil e juvenil na prática docente. Rio de Janeiro: Ao Livro Técnico, 2010. p. 39-53.

SILVA, Ariana Nobre; ALBUQUERQUE, Maria Aparecida Domingues. A literatura infantil na sala de aula e fora dela. In: BOLZAN, Doris Pires Vargas (Org.). Leitura e escrita: ensaios sobre alfabetização. Santa Maria: Ed da UFSM, 2007. p. 55-61.

SOARES, Angélica. Gêneros literários. São Paulo: Ática, 2003. p. 84-86.

Recebido: 20 ago. 2017

Aprovado: 12 set. 2017

DOI: $10.3895 /$ rl.v19n26.6962

Como citar: ANTUNES, Tiana Andreza Melo; OLIVEIRA, Thaís Martins de. A literatura infantil em sala de aula nos anos iniciais: a importância dos contos. R. Letras, Curitiba, v. 19, n. 26, p. 16-33, set. 2017. Disponível em: <https://periodicos.utfpr.edu.br/rl>. Acesso em: XXX.

Direito autoral: Este artigo está licenciado sob os termos da Licença Creative Commons-Atribuição 4.0 Internacional.

$$
\text { (c) (1) }
$$

